\title{
Ecology mechanism of female talents social mobility
}

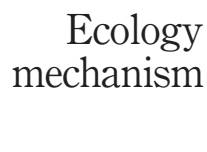

\author{
Yun-na Liu \\ Tianjin University, Tianjin, China and Tianjin University of Technology, \\ Tianjin, China, and \\ Zhiyu Liu \\ Secondary Music School Affiliated to Tianjin Conservatory of Music, \\ Tianjin, China
}

Received 7 December 2020

Revised 6 March 2021

Accepted 6 March 2021

\begin{abstract}
Purpose - With the development of social economy, the problem of female labor force and talent ecology mechanism has become increasingly prominent. They do not assign jobs according to their abilities, but decide their duties according to their interpersonal relationships. The uneven distribution of human resources makes the difference, the impact of the female talent social mobility tends to solidify and the social strata between the contradictions are deepening.

Design/methodology/approach - This paper mainly investigates the current situation of female talents social mobility to solve the problem of the social mobility of female talent, and evaluates the main factors that affect female talents social mobility by analyzing the flow of ordinary female labor, enterprise female talents and educational female talents.

Findings - Society should pay attention to the social mobility of female talent, carry out comprehensive ecology mechanism in time, take different methods to the management of female talents in different industries, remove the obstacles that affect the social mobility of female talents and create a good ecology mechanism of female talent.
\end{abstract}

Originality/value - This paper provides corresponding suggestions and countermeasures on the ecology mechanism of female talents social mobility.

Keywords Female talents, Social mobility, Ecology mechanism

Paper type Research paper

\section{Introduction}

Talent is a person who has some special knowledge or skill in social practice and has made contributions or great achievements in understanding and reforming some aspects of nature and society. Talent waste is an intent social incident in the human times past (Peng and Lan, 2015). Female talent flow refers to the migration and flow of female labor force and talent in different geographical areas and different jobs. On the macro level, it belongs to the problem of human resource allocation and reconfiguration. The general flow refers to the change of female labor or talent from one working state to another, and the working state can be determined according to the position of the work, the location of the work, the nature of the

(C) Yun-na Liu and Zhiyu Liu. Published in Ecofeminism and Climate Change. Published by Emerald Publishing Limited. This article is published under the Creative Commons Attribution (CC BY 4.0) licence. Anyone may reproduce, distribute, translate and create derivative works of this article (for both commercial and non-commercial purposes), subject to full attribution to the original publication and authors. The full terms of this licence maybe seen at http://creativecommons.org/licences/by/4.0/ legalcode

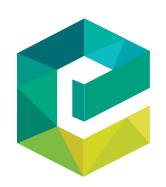

Ecofeminism and Climate Change Vol. 2 No. 2, 2021 pp. 103-108 p-ISSN: 2633-4062 e-ISSN: $2633-4070$ DOI 10.1108/EFCC-12-2020-0036 
EFCC

2,2

104

profession, the object of the service and its nature. The flow of human resources in a broad sense includes not only the flow of female labor and talent among departments, enterprises and even industries but also the flow of female labor and talent in enterprises and departments, and the introduction of foreign learning or skill knowledge is the intellectual flow of human resources. The essence of human resource flow is the process of recombining workers with means of production.

\section{Current situation of the social mobility of female talents in China}

With the deepening of modern economic and social development, female talent exchanges have become increasingly common and frequent. This is a reasonable demand for scientific allocation of human resources in modern society, which is in line with the trend of the times. With the continuous development of China's market economy and growing prosperity, its demand for female talents is also increasing. Whether it is from the political angle of ensuring social stability or promoting the economic development of social and economic development, the rational distribution of social resources and improving the efficiency of human resource allocation has always been a concern. Border closures increase the unemployment rate and decrease out-migration (Adnan, 2015). The social environment impacts the behavior of female talents (Gangadharan et al., 2019). From the present situation of China, the problem of female labor and the social mobility of female talent need to be solved urgently.

If the social female talents are concentrated in a certain region, the country will easily have problems such as uneven regional economic development, low human resources allocation efficiency, social contradictions and the gap between the rich and the poor and so on. There are various reasons that affect the flow of female talents in China, and there will be differences between different industries. Researches of Female business leaders and economic performance are seldom conducted with global observational figures and business environment consideration (Fang et al., 2020). Accounting investigators illustrate insignificant gender differentiations (Gago and Macias, 2015). But in general, the problem of social class solidification is universal.

\section{Factors affect the female talents social mobility among different industries}

The questionnaire survey is conducted to 3,871 female talents in China. They were selected because they have characteristics that enable a detailed exploration and understanding of the research purpose. When selecting, three stated-owned enterprises, three private companies, four public/government sections and five universities/colleges/schools were included in looking at the differences in organizations size (small, medium and big), different industries (manufacturing, service and retail) and different locations (rural and urban) (Table 1). The data collection took place between March 12, 2019 and August 25, 2019. In addition to the survey, the interviews were conducted as the same time and in Table 1 , there are the positions of the interviewees. After the questionnaire survey to 3,871 female talents in China, this paper summarizes the key ecology factors that affect the social mobility of migrant female talents, enterprise female talents and female teachers as following.

\subsection{Factors affect the migrant female talents social mobility}

3.1.1 Development of new urbanization is difficult. The problem of people's livelihood has always been the focus of the work of the party and the government, and the mobility of the migrant workers is also deeply concerned. In the course of the new urbanization, the contradictions between the rural residents and the urban residents have always existed, and the urban residents have excluded the rural residents, and the rural residents can hardly 


\begin{tabular}{|c|c|c|c|c|c|c|}
\hline & Ownership & Size & Industry & Location & Interviewees position & $\begin{array}{l}\text { Ecology } \\
\text { chanism }\end{array}$ \\
\hline 1 & Stated-owned enterprise & 100,000 & Manufacturing & Urban & General Manager & \\
\hline 2 & Private company & 20 & Retail & Rural & Owner & \\
\hline 3 & Public company & 2,000 & Service & Rural & General Manager & \\
\hline 4 & Government & 300 & Service & Rural & Director & \\
\hline 5 & University & 1,000 & Service & Urban & Professor & \\
\hline 6 & College & 500 & Service & Urban & Lecturer & 105 \\
\hline 7 & School & 300 & Service & Urban & Teacher & \\
\hline 8 & Private company & 100 & Retail & Urban & General Manager & \\
\hline 9 & Stated-owned enterprise & 80,000 & Manufacturing & Urban & General Manager & \\
\hline 10 & Stated-owned enterprise & 10,000 & Retail & Rural & Sales Manager & \\
\hline 11 & Government & 500 & Service & Urban & Director & \\
\hline 12 & Private company & 1,000 & Manufacturing & Urban & Manufacturing Manager & Background of the \\
\hline 13 & Public company & 10,000 & Service & Urban & General Manager & questionnaire survey \\
\hline 14 & University & 3,000 & Service & Urban & Dean & represents and \\
\hline 15 & School & 100 & Service & Rural & Principal & interviewees \\
\hline
\end{tabular}

change their original way of life for a time. The vertical movement of villages to cities is impeded and the process is rather slow.

3.1.2 Household registration system restricts the female talent social mobility. In a city, there is a big gap between the household registration and the non-registered population in terms of employment opportunities, salary levels and social welfare benefits. Take Tianjin as an example. Before this year, Tianjin locals enjoyed all the preferential benefits provided by all the countries in Tianjin, but the foreigners wanted to buy a house in Tianjin, and the house had some requirements to be eligible to settle down. This situation greatly limits the flow of female talent in the field.

3.1.3 Lack of standardized management of female talent ecology mechanism leads to unfair competition in the female labor market. Local governments usually consider the employment problem of local female labor force first, so there will be a discriminatory employment problem for migrant workers. The defects of the female talent market mechanism lead to the low efficiency of the allocation of social resources and human resources, the few kinds of work that the migrant workers can engage in and the unequal competition with the middle class and the upper class, and the gap is becoming more and more large.

3.1.4 Public services and social welfare inequity restrict migrant female talents' mobility. The allocation of educational resources in urban and rural areas is not balanced. The distribution of educational resources in rural and urban areas is uneven, and the starting line of students is also different. On the other hand, the social welfare, the mobility of female workers is larger, and the relatively stable welfare insurance cannot be obtained in the other fields. These two aspects have also become the restrictive factors that affect the migrant female workers' flow.

\subsection{Factors affect the mobility of female talents in enterprises}

There are many people who choose job hopping every day in the enterprise, and the flow of female talent is common to the enterprise, but the brain drain has a great influence on the economic development of the enterprise. There are three main reasons for the flow of female talents in enterprises: 
EFCC

2,2

106

3.2.1 Salary and welfare of staff and workers. The reason that most employees choose job hopping is that the salary of another company is higher than that of the present. After all, most people work to survive and choose the job as well. They want their own pay and harvest to be proportional to it, so the enterprise female talent will be given a fair and encouraging shadow of the company's salary system.

3.2.2 Flow of female talents will be affected by the company's training for employee. In a company, there is a large gap between the senior staff and the underclass employees, including their treatment, work environment, knowledge and skills, which lead to poor mobility and distinct stratification. Employees at the bottom level need to make a lot of efforts and fail to reach the level of senior staff, so staff training is very important for employees.

3.2.3 Impact of job satisfaction on the flow of female talent. Job satisfaction includes job fitness and job satisfaction. One is to put the right staff in the right position; the other one is to match the position of the employee and his ability, so that his ability is fully applied. If employees don't like his work, they can't get into their work wholeheartedly, they may choose to leave, as well, let a talented person do a boring and boring job, he feels buried and will also choose to leave the company.

\subsection{Factors affect the mobility of female teachers}

3.3.1 Female teachers have different professional knowledge. Young teachers and primary school teachers pay more attention to the children's enlightenment education, junior and high school teachers are concerned about the basic knowledge of the students, primary teachers generally grasp the corresponding academic knowledge enough. But college teachers pay more attention to the practical and academic ability of students. With the position selection performance system in China, faculty is more movable than before in educational marketplace (Yan et al., 2015).

3.3.2 Long-term planning of female teachers' professional development is insufficient. Although some schools have a plan but just do it, they are only used to cope with the inspection and evaluation. They have not been effectively planned according to the actual situation of their own schools, that is, it is not feasible.

\section{Measures to improve the social mobility of female talents}

\subsection{Reform the household registration system}

Household registration system reforms assisted in eliminating talent market segmentation (Song and Li, 2015). To promote the social mobility of female talents, the government should abolish various policies and regulations to restrict the flow of population as soon as possible, improve the employment conditions, establish the social security mechanism of urban and rural co-ordination, abandon the local protectionism, and gradually establish the integrated female labor market in urban and rural areas and realize the factors of female labor force among industries and regions. Guangdong, Shenzhen and Tianjin have issued relevant regulations on household registration reform. The reform of the household registration will help to attract more people to attract more people, reduce the inequality of employment, promote social equity and provide employment opportunities for more female labor, and break up the barriers to employment and all kinds of discriminatory employment policies.

\subsection{Promote the equalization of basic public services and prevent the disadvantaged sectors from losing their mobility}

This is mainly for the protection of the basic survival and development of the disadvantaged strata, and the special nature of the disadvantaged class also makes them lack many basic 
guarantees. Migrant workers, such as migrant workers, often face difficulties in medical treatment, difficult medical treatment, expensive medical costs and their poor salaries in sharp contrast, and they cannot enjoy the local welfare in the field, social insurance and personal insurance cannot be guaranteed. The disadvantaged class has a low starting point, low technical level, no competitive advantage and the basic public services of education and culture are unable to meet their needs. Therefore, both the government and the society should give them help to allow more disadvantaged classes to enjoy the treatment equally.

\subsection{Design good social insurance system of the female labor force}

In the choice of social insurance system, it should fully consider the characteristics of its mobile employment, distinguish between stable employment and unstable employment groups and realize the protection of stratified classification. For the stable employment female labor, the social insurance system of the current urban workers is gradually incorporated into the current urban workers' social insurance system, and the transitional measures can be taken into consideration for the female labor force of the unstable employment. The pension insurance can establish individual accounts to facilitate the transfer, and the insurance should be brought into the present form, and the medical insurance should be properly adjusted under the current system.

\subsection{Implement the education and training of female labor force}

Whether the female labor force can achieve effective vertical mobility depends largely on the improvement of female labor quality and skills. Governments at all levels should include female labor training on the agenda of the government, increase investment and establish the investment mechanism of government, enterprise workers, social sharing and multichannel financing. The government should actively carry out the corresponding education and training work. In view of the needs of the market and enterprises and the characteristics of the female labor force, the government should focus on the training of employment skills, enhance the pertinence and applicability of the training, make it master the necessary skills and knowledge and obtain the corresponding qualification certificates and constantly improve the practical employ ability.

\subsection{Strengthen ecology mechanism of female talents to achieving vertical mobility in the society}

4.5.1 In the enterprise, the company should attach importance to employees' salary and welfare and staff training, and create a fair competition environment. Implement salary incentive system, actively carry out staff training activities, create good growth environment for employees, strengthen employees' skills, improve their ability to deal with business and personal cultural accomplishment and make them low skilled workers can also acquire the knowledge possessed by senior staff, carry out competition posts and post exchanges and speed up personnel training. Competition posts and job exchanges are based on exploring the advantages of female talents within the enterprise, thereby promoting the development of enterprises. The implementation of the competition is conducive to promoting the outstanding young female talents within the enterprise to stand out, mobilize the enthusiasm and enthusiasm of the employees for long-term precipitation, so as to see the future of the common development of enterprises and employees.

4.5.2 Respect female talents' efforts to establish a good ecology mechanism. The identity management system covers all the information of a citizen, and makes a classification of citizens, such as farmers, ordinary workers, technicians, civil servants and so on. What have 


\section{EFCC}

2,2

to do is to respect the achievements of every worker's efforts, eliminate social discrimination, affirm the efforts of the workers, innovate the employment mechanism, encourage more people to work on the ground and encourage the people's awareness of innovation and guide the young people to set up the correct values, the concept of career selection and the concept of employment. To avoid the adverse effects of some non-mainstream cultures in the network, abandon the bad habits of work and work, let more people work knowledge and innovation and create a good social atmosphere and public opinion environment for the flow of female talents, and lead the elite to flow to the upper class.

\section{Conclusion}

The social mobility of female talent is like the blood in the human body. Only by continuous flow and continuous metabolism, the human body can keep healthy. Ecology mechanism also needs a variety of female talent flow to bring new vitality, promote economic development and social progress. Social stratum solidification as blood clots in blood vessel fortress, the long time will cause a variety of diseases. A country or an enterprise needs to pay attention to the importance of vertical flow, to solve the blood clots in a timely manner, let the blood flow smoothly and let the outstanding female talents play their female talents in the right position. Society should pay attention to this problem, carry out comprehensive ecology mechanism in time, take different methods to the management of female talents in different industries, remove the obstacles that affect the social mobility of female talents and create a good ecology mechanism of female talent.

\section{References}

Adnan, W. (2015), "Who gets to cross the border? The impact of mobility restrictions on labor flows in the West Bank", Labour Economics, Vol. 34, pp. 86-99.

Fang, S., Goh, C., Roberts, M., et al. (2020), "Female business leaders, business and cultural environment, and productivity around the world", Policy Research Working Paper Series.

Gago, S. and Macias, M. (2015), "A possible explanation of the gender gap among accounting academics: evidence from the choice of research field", Accounting and Finance, Vol. 54 No. 4, pp. 1183-1206.

Gangadharan, L., Jain, T., Maitra, P., et al. (2019), "Female leaders and their response to the social environment", Journal of Economic Behavior and Organization, Vol. 164 No. 8, pp. 256-272.

Peng, L.Q. and Lan, Y. (2015), "The countermeasures to reduce and avoid stifling talents: from the perspective of managers", Higher Education of Social Science, Vol. 8 No. 4, pp. $43-47$.

Song, J. and Li, S. (2015), "Hukou's impact on labor occupation segmentation", China Agricultural Economic Review, Vol. 6 No. 3, pp. 651-672.

Yan, G., Yue, Y. and Niu, M. (2015), "An empirical study of faculty mobility in China”, Higher Education, Vol. 69 No. 4, pp. 527-546.

\section{Corresponding author}

Yun-na Liu can be contacted at: liu.yunna@hotmail.com

For instructions on how to order reprints of this article, please visit our website:

www.emeraldgrouppublishing.com/licensing/reprints.htm

Or contact us for further details: permissions@emeraldinsight.com 